\title{
Retraction
}

\section{Retracted: Light-Induced Tyrosine Radical Formation from Ruthenium-Tyrosine Complex Anchored to $\mathrm{SnO}_{2}$ Semiconductor}

\author{
International Journal of Photoenergy \\ Received 24 August 2020; Accepted 24 August 2020; Published 28 November 2020 \\ Copyright (c) 2020 International Journal of Photoenergy. This is an open access article distributed under the Creative Commons \\ Attribution License, which permits unrestricted use, distribution, and reproduction in any medium, provided the original work \\ is properly cited.
}

International Journal of Photoenergy has retracted the article titled "Light-Induced Tyrosine Radical Formation from Ruthenium-Tyrosine Complex Anchored to $\mathrm{SnO}_{2}$ Semiconductor" [1], as it is essentially identical in content with a previously published paper [2]. In particular, the article contains identical figures (namely Figures $4 b, 5 a$, and $5 b$ ) with the above mentioned paper. While in the earlier published paper, the figures described the $\mathrm{Ru}$-complex attached to $\mathrm{TiO}_{2}$, the same figures have now been used in this article to describe the electron transfer between the $\mathrm{Ru}$-complex and the $\mathrm{SnO}_{2}$ semiconductor.

\section{References}

[1] R. Ghanem, "Light-Induced Tyrosine Radical Formation from Ruthenium-Tyrosine Complex Anchored to $\mathrm{SnO}_{2}$ Semiconductor," International Journal of Photoenergy, vol. 2008, Article ID 524142, 7 pages, 2008.

[2] Y. Xu, J. Pan, T. Hoffmann et al., "Light-Driven Tyrosine Radical Formation in a Ruthenium-Tyrosine Complex Attached to Nanoparticle $\mathrm{TiO}_{2}$," Inorganic Chemistry, vol. 41, no. 24, pp. 6258-6266, 2002. 